\title{
Assessment and Analysis of Locating Housing and its Impact on Development Patterns in Damghan
}

\author{
Ahmad Arjmand1* and Barat Ali Khakpoor2 \\ 1PhD Student in Goegraphy and Urban Planning Ferdowsi University of Mashhad, Mashhad, Iran \\ 2Associate Professor of Geography and urban planning, ferdowsi University of Mashhad, Iran \\ *Corresponding author E-mail: arjmand1414@gmail.com
}

\begin{abstract}
Understanding and management of urban street space capable of lighting it creates Urbanization process can be observed today in all countries this process, if it is considered natural and less worrisome, but if unplanned, the impaired and the ultimate goal is the welfare of citizens is not. Today, one of the problems of our cities and urban poor urban adverse effects that urban planning is a serious subjects. The aim of this study was to investigate locating housing and its effects on the development directions of Damghan. The research method based on purpose and on the basis of a descriptive nature that is the case in this study, the analytical hierarchy process (AHP) and Microsoft Excel and SPSS statistical analysis is used to produce tables.
\end{abstract}

Keywords: pattern of development, localization, housing, Damghan.

\section{Introduction}

Location of land suitable for urban development, housing is one of the most important factor. A variety of factors and forces involved in locating and forming settlements. Locating, selecting the best place to do an activity that can be used in the most efficient facilities in order to provide a pre-determined objectives.logic, decision-makers and planners to assist in selecting suitable place or location.

The need for housing is both qualitative and quantitative. After a bit in need of housing, the lack of shelter and access to housing and quality issues and phenomena that arise after the homelessness, housing Bdmskny and tight lead. There are inadequate housing units known as Bdmskny, the social problems of today's society. Residential areas to ensure correct positioning of the housing shortage and lack of proper attention to the criteria of physical, social, economic, etc., causing a lack of full implementation of the plans and objectives envisaged for the loss or dissatisfaction residents will be spending. The correct location of housing is one of the most important parts of planning and time and cost of housing for housing leads to more successful projects and reduce the cost of the future. Meanwhile, today the volume of data in different areas and how to analyze them for decision making and planning is more complicated. The need to organize the data and create a database with comprehensive and timely. All information management and the impact of the outreach plan and procedure, physical development, natural conditions and social and humanitarian situation, notice of a variety of natural disasters and crisis management, economic status, such as employment, income and quality of data and a bit of ability Experts will be beyond the mind, the mathematical and statistical analysis and the use of different models, especially AHP AHP facilitates locating residential areas.
The overall objective of this study include: facilitating the integration of multiple criteria and sub-criteria decision making large-scale scientific model and appropriate positioning of residential space and residential space in the right location with the use of the Analytic Hierarchy Process (AHP). The criteria and sub-criteria for the operation to achieve the patterns and the location of residential areas describes the location of residential areas in view of the priority factors through AHP models noted.

\section{Locate and Process Definition}

Location on the earth sciences, in which the individual operations specialist to see the needs, objectives and status information available to other experts, such as traffic, economics, sociology, psychology, geography, geology, Hvshnasy, biology and wrap it in the form of ideas and goals for achieving the best selection of choices available to the user in question. Optimal location when possible, the researcher will be given priority scientific and reasonable correlation between data obtained from relevant experts establish the location (FAZELNIA et al. 1389, 5). Man to bear the cost, make more profit and ease of access to resources, location elects its activities. But with more complex factors in location, to have to use scientific methods and modern (especially after World War II) is turned. In this theory, theories and models proposed was that each has advantages and disadvantages for particular applications have been considered. Most of these theories focus on some of the factors affecting the process of navigating. In terms of attitude and policy analysis theory locations are divided into three categories:

Nzryh Based on least cost (Lanhard, Weber, Hoover) -Nzryh-Based analysis method of access (more emphasis on demand and market factors and maximizing revenue is concerned) Los August.

-Nzryh Method based on maximum profit and the logical consequence of the above methods (Walter Ayzard, Green, Hart). 


\section{Methods}

The research method based on purpose and on the basis of a descriptive nature that is the case in the review, prioritization criteria for the location of residential areas was conducted using AHP model. In this section we review criteria in the literature, due to the multiplicity and limitations of the data, as well as the construction of which makes some analysis of studies (such as the analysis cultural) incomparable Impartiality. Were summarized and key metrics in this study are just. Then set the standards in the form of a questionnaire and were distributed between the experts of urban development. Then the results obtained for pairwise comparison of criteria and sub-criteria that were averaged. And in the following matrix (matrix calculation, the points are Thomas L. hour) based on AHP criteria and sub-criteria were ranked on each criteria. Total results at the end of the process and in Table 1 below. The Figure (1) criteria and sub-criteria review the hierarchical tree shows the location of Damghan housing land.

\section{Analytical Hierarchy Process (AHP)}

Analytical Hierarchy Process (AHP) is a flexible, robust and simple to make decisions in the absence of conflicting decision criteria makes it difficult to choose between options, is used. The multi-criteria evaluation method, first proposed in 1980 by Thomas L. hour and has had numerous applications in various fields. Means the process of hierarchical analysis. Selection criteria or criterions AHP is the first part of the analysis.

The candidates are evaluated on the basis of identified criteria Compare couple different criteria with respect to the objectives and criteria to determine the relative weight of this third step: collecting the data in relation to the criteria for each of the options Step four: Compare couple different options for each of the criteria and the relative weight of Options for each of the criteria fifth step: analyzing the results to determine the final weight of each of the options and priorities of each of them one of the most multicriteria decision-making applications, their use in decision-making group. Fundamentals of Analytical Hierarchy Process - adverse condition (Reciprocal Condition) Agrtrjyh element A to element B $\mathrm{n}$ be the preferred element to element $\mathrm{A}, \mathrm{B}, \mathrm{n} / 1$ will be. - The principle of homogeneity (Homogeneity) ingredient A with ingredient B should be homogeneous and comparable. In other words, the lead element A to element B can not be infinite or zero. - dependency (Dependency) each hierarchical element to element level can be linearly dependent and this dependence has the highest level can be continued. Expectations (Expectation) whenever changes occur in the structure of hierarchical evaluation process should be done again.

\section{Research Questions}

1. criteria and sub-criteria which are locating residential areas? 2. How can the criteria and sub-criteria using AHP prioritized? 3. Is the location of housing is properly Damghan

\section{Range Studied}

Shhrdamghan between 53 degrees and 42 minutes to 45 degrees and 49 minutes east longitude and 36 degrees 34 minutes north latitude in the world. The city is bounded on the north by the Alborz Mountains and south to the desert and from the West and from the East to the city of Semnan city anymore. Damghan, Semnan on the southern slopes of the Alborz and $120 \mathrm{~km}$ East and is located $70 \mathrm{~km}$ West anymore. Much of the area of the city of Damghan the plains and the mountains to the other. The highest point of the city, the Peak is the height of 3813 meters above sea level in the mountains of Alborz mountain range Srtng.h from the lowest point, $1063 \mathrm{~m}$ above sea level, which is located in the desert south of Damghan well in the Cup. Damghan is plain from north to south gradient wells Cup, to the desert of height is reduced again until low mountains in the south, holes or plain cover from the desert, separates. Geologically, the oldest organization of land cover is related to the Precambrian period. The tectonic structure of schist, gneiss and other metamorphic rocks are. Damghan in northern mountains to the southwest of the northeast there are several faults with that observed in the creation of buildings and other facilities necessary for the occurrence of earthquakes (Venerable, 1390, 123).

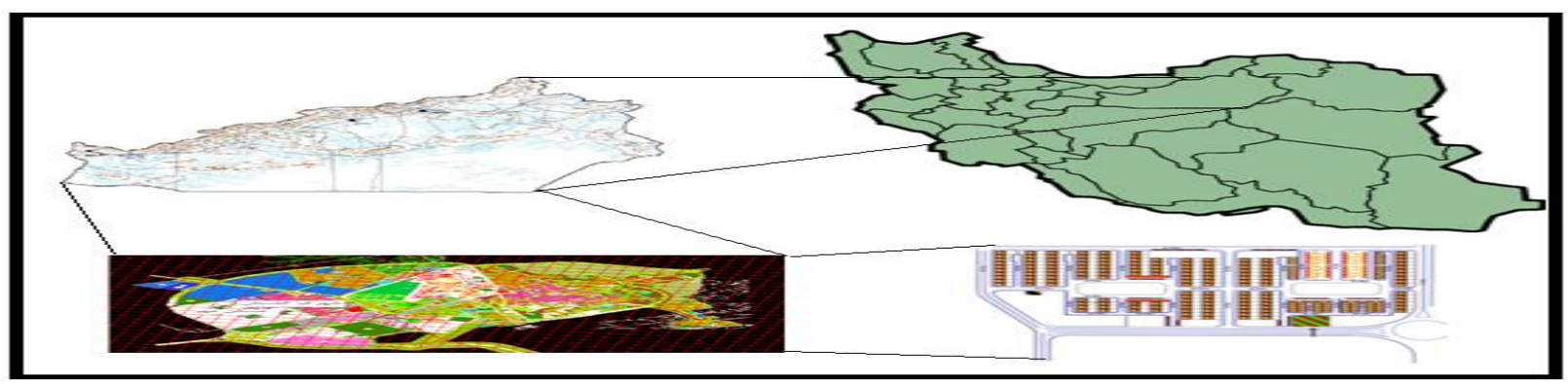

Map 1: Location and areas of Damghan

\section{The Introduction of Criteria and Sub- Criteria for the Location of Residential Land}

Concepts for use of empirical measures need to be converted, in the process of conceptualizing (3), which in fact is a fact to understand the abstract concept, Does not pay attention to all aspects of reality, but only to emphasize the aspects that is the principal investigator. The process of making meaning is generally include the following: Step One: Determine the dimensions of the concept, the second step: Determination of criteria (4) to help it assess the size of the measure. In fact, signs of objective and measurable criteria of concept (Earth, 1378: 75). Step Three: Creating varia- bles (5). In simple words we can say that is variable from one person to another attribute changes (Taleb, 1370: 76). In this study, rather than variable dimensions and criteria, sub-criteria have been introduced.

\subsection{Criteria and Sub-Criteria to Locate Residential Ar- eas}

As also mentioned in the approach and methodology, this study is part of the macro-location of housing projects across the country by the Center for Urban Development and Architecture Department of Urban Studies and research have been conducted. The criteria and sub-criteria to extract the location of residential land after preliminary studies by experts in architecture and urban stud- 
ies center consists of key criteria and sub-criteria were defined. In this section, set basic issues related to separation criteria and subcriteria in terms of location of residential land proposed to be addressed: physical, social - cultural, economic, ownership and legal standards, environmental, site value, access and status of land, civil defense operating and security. Of course, given the complex and extensive issues of socio-cultural, economic and defense and the need for more specialized focus on the development of these criteria and sub-criteria relating to it in this article and not merely as primary and the role of location in a residential area is limited.

\subsubsection{Measure the Value of the Site:}

Fit the size, form and shape of the earth, the user matches the aesthetics of neighborhoods and within the key factors determining the value of land designated for residential development site. In this investigation, the views to the outside in and the inside out are identified and analyzed in the tables. And the goal is that the residential location (such as residential areas, tourism) These criteria can be more important as well and in the process receive priority weighting relative to other criteria

\subsubsection{The Following Criteria for the Site:}

Fit the size, form and shape of the site and according to the situation and taking advantage of the difference in surface topography to create a vision and a better view of the above and considering the visual diversity of natural landscapes (sea Vdryachh, mountains, trees of the arable land etc.) lack Close Jdyddm see the development of visual contamination and ugly scenes outside the site that ugly face Bamhyt Vnahmahng natural surroundings and reduce the value of the visualization area

Considering the consistent development of regional identity and residential context with the natural and cultural features (for example, the possibility of using local materials and traditional residential architecture model combined with modern methods in a way that is acceptable to residents)

User agrees neighborhoods site (center of study and research of the architectures, 1389).

\subsubsection{Environmental Criteria:}

Although the environmental standards of the most important and most fundamental ecological principles that should be strongly considered in any location, are often neglected. In addition, with respect to sustainable development policies will be increased attention to environmental criteria. Having the ability to develop green areas (especially in the theory of the creation of residential Baghshhrhay) is another important factor in location will be very effective. The selected area should be away from hazards and environmental damage, such as flood, earthquake, storm, sand and pathogenic environment. In this connection, comfortable living conditions should be accompanied during the year. Another thing that can be used as an environmental measure, due to the contamination of the environment.

\subsubsection{Environmental Sub-Criteria:}

Mvqyt Natural sites in the region and to consider the human being with the ability to develop green areas (especially in the theory of the creation of residential Baghshhrhay) - Natural hazards and comply with environmental pollutants and respect privacy . What residential neighborhood in locating areas reduce or eliminate environmental pollution such as noise pollution, air pollution and taking into account the dominant wind direction according to sustain the environment (center for the Study and research of Urban Planning and architecture, 1389).

\subsection{Access and Position Location}

\subsubsection{Standard Physical}

The physical dimensions of the housing is two-fold. First, as a body housing and the second housing unit, housing and physical relationship with their home environment to a social index and the role of housing in urban development raises. For example, the location of housing is of particular importance. Different income groups that can afford to provide and purchase housing. Nabavi, 1384: 41). Urban living in different places (Tawfiq, 1369: 1 and 2). The selected location for residential usage should land with a slope of 1 to $8 \%$, the maximum height of 1,600 meters, known faults in the area of privacy, privacy stream so that within 50 to 300 meters of building space each residential prevent species (Gharagozlou, 1384, p. 25). Another very important factors to consider in locating the soil and topographic conditions is sufficient to promote development activities in a way that requires a minimum of leveling and excavation have, and the permeability enough (Tavakkouli)

\subsubsection{Sub-Criteria Framework}

including basic infrastructure including access to water, electricity, sewage network, access to the telecommunications network 3 ) the possibility of growth and physical development of space-there Bna- Kafy- soil and the possibility of access to building materials native (center for the Study and research of Urban Planning and architecture, 1389).

\subsection{Ownership and Legal Criteria:}

It can be an economic concept and describes the economic situation of households, but also social and cultural aspects studied (Azizi, 1383: 36). States with land allocation to low-income groups are trying to increase economic equality. In the absence of government intervention in the land market in urban, low-income families barely have the ability to access land for housing. Therefore, government intervention in the land market principles accepted in all countries. The method can be used to capture and supply of land, restrictions on the ownership of land, land-use laws and regulations on land owned by the private sector and the tax laws and regulations affecting the decisions of the private sector's transactions and land use (Rafeie, 1382: 45). Legal status of certain lands and areas surrounding the use of the most important things that must be considered and the emphasis placed in any location.Even in cases where the choice of public lands and public areas is, may exploit such rights of indigenous peoples traditionally they have ascribed to themselves. What is certain is that the land allocated to the Official Rules and the common law, the situation is quite clear they (Islamic Revolution Housing Foundation, 1389). The maps of land ownership and legal issues (national, dead, endowment, buy, deal, Maliki etc.) is essential.

\subsubsection{Land}

Near the site of the city and municipal services (employment, training, health care, sports and leisure, etc.) and access to a network of passages such as distance area networks (road) and terminals and graded them importance on a national, provincial, regional, local, territorial distance to the rail network and railway stations, the distance of the land to the rail network and railway stations, the distance to the airport or land port of Determine the appropriate access are important residential site. In fact, many of the sites and residential projects because of lack of attention to this important factor should be performance degradation and lose their applicants. 


\subsubsection{Sub Criteria and Positioning Access to the City}

Ease of access to anything else settlements near the site of the city and municipal services (employment, training, health, sports and leisure, etc.) - Access to the network of passages such as distance area networks (road) and terminals and ranking them in terms of importance on a national, provincial, regional, local, territorial distance to the rail network and railway stations, the distance to the airport or land port. (Center for the Study and Research of Urban Planning and Architecture, 1389).

\subsubsection{Need Situation and Respect the Privacy Initiatives and Outreach Programs:}

One of the very important location in the upper area check the status of all projects, including project planning, strategic, comprehensive, detailed, thematic and local initiatives so it is with the position of the sites. Also note the position of the land and that is within the city. Or within the country or territory and if it is not in the range mentioned above, the minimum distance from the nearest town or village, what amount should be. The other key privacy anticipated in projects ranging from the privacy of facilities, green space and natural hazards and energy resources and so on.

\subsection{Scale Socio - Cultural:}

Among the criteria to evaluate the optimal location of housing, social satisfaction criteria, the most appropriate means of measuring progress and the realization of the overall objective of housing. On the other hand, in an ideal situation, social housing criteria should be developed in such a way that expansion and economic criteria and other criteria that are necessary for the decisions, in this regard, be proportionate. Somewhat indicators that can assess the response to these needs include: Surfaces that are awarded to each individual, but for households with incomes below this level will be lower (Habibi and others, 1367: 81). Housing is planning some kind of social engineering where trying to be agreed common objectives of society. Which is reflected in documents such as the constitution. Realized at a certain time. Failure to realize future research goals, in addition to increasing poverty and human development can cause delays or disruption of social consensus, too (Rafeie, 1382: 54).

\subsubsection{Social Sub-Criteria - Cultural}

Sufficient population and balanced proportional composition of different age groups

and sexual identity According to the Iranian model - Islamic ties due to ethnic, religious, tribal and other physical proximity and within residential neighborhood - Matching the socio-cultural background (Islamic Revolution Housing Foundation, 1389).

\subsection{Economic Criteria:}

One of the factors factor Mhtryt housing is an economic factor. Some of the main economic issues affecting the location of residential areas include: the price of land, according to the employment needs of different groups according to age and sex and forecasts and unemployment rates, per capita, according to the building, considering the demand for housing the target sites, access to local markets and urban and financial institutions credit (local funds, banks, etc.).

\section{The Calculation of Scores for the Prioritiza- tion Criteria}

A) physical B) Environmental C) access and opportunity to the city D) Value Site E) ownership matrix comparing the two criteria location A) physical: $73 / 1=(1 \times 4 \times 7 / 1 \times 5 \times 6)^{\wedge}(5 / 1-B)$ environmental: $\left.89 / 1=(3 / 1 \times 1 \times 3 / 1 \times 4 \times 6)^{\wedge}(5 / 1)-C\right)$ and access to the city's position: - D) Value Site: $002 / 0=(5 / 1 \times 5 / 1 \times 7 / 1 \times 1 \times$ $3 / 1)^{\wedge}(2 / 1)-$ E) ownership: $38 / 0=(7 / 1 \times 5 / 1 \times 9 / 1 \times 1 \times 3)^{\wedge}(5 / 1$ After normalization coefficients obtained for the criteria: Physical: - Environmental: 23/0 C) access and opportunity to the City: 51/0 $\begin{array}{llll}\text { D) Value Site: } 003 / 0 & \text { E) ownership: } 81 / 0\end{array}$ 1-8-matrix prioritization of sub-criteria for each criterion 1-1-8- physical standard: comparison matrix rating criteria, subcriteria related to physical Slope and topography: $1=(1 \times 7 \times 7 / 1)^{\wedge}(3 / 1)$ - are infrastructure services: $1=(7 / 1 \times 1 \times 7) \wedge(3 / 1)$. Possibility of construction: $62 / 3=(7 \times 7 \times 1) \wedge(3 / 1)$ Coefficients obtained for the criteria so Aznrmalyz-h out: Slope and topography: $16 /-0$ existence of infrastructure services: 19 / - -0 possibility of construction: $68 / 0$

\subsubsection{Environmental Criteria}

Rating criteria, sub-criteria related to environmental comparison matrix

Closely with environmental pollutants: $24 / 2=(1 \times 5)^{\wedge}(2 / 1)-$ the lack of natural hazards: $7 / 0=(5 / 1 \times 1) \wedge(2 / 1)$ Coefficients obtained after normalization criteria: Closely with environmental pollutants: 76 / -0 natural hazards: $23 / 0$

3.1.8. Measure of Site Value: Comparison Matrix Points the Following Criteria to Benchmark the Site

\subsubsection{Land}

Land ownership criteria, sub-criteria related to national land matrix scores:

$3=(3 \times 7)^{\wedge}$

Coefficients obtained after normalization criteria: national territory: 1

According to the criteria and sub-criteria to prioritize normalized coefficients as follows

\section{The Ecological Situation of the Project Site}

\subsection{Close of Environmental Pollutants in the Field of Environmental}

pollutants, according to Housing and Urban Development Semnan Province, two projects are exposed to industrial pollution emissions, but their privacy is respected. The entire space for housing projects in Damghan have been fully respected.

\subsection{Lack of Natural Hazards in the Survey Conducted}

By the Housing and Urban Development Semnan Province, found that the site near the fault not of the housing. And risks such as floods, earthquakes, landslides, etc. It does not threaten residential areas.

\subsection{Status Respond to Physical Criteria}

Possibility of construction: Housing Damghan site soil was suitable for the construction of housing and a good location are of the opinion (Housing and Urban Development Semnan Province). Slope and topography: Based on the slope and topography data on housing projects in Damghan, Drarazy flat with gentle slope of 1 to 4 percent. 
Table 1: the criteria and sub-criteria to prioritize locating housing

\begin{tabular}{|c|c|c|c|}
\hline , sub-criteria priority & priority criteria & , sub-criteria & Criteria \\
\hline 2 & slope & \multirow{3}{*}{1} & \multirow{3}{*}{$\begin{array}{l}\text { A } \\
\text { Physical }\end{array}$} \\
\hline 2 & There are infrastructure services & & \\
\hline 1 & Possible construction & & \\
\hline 1 & of nearby ecological Baalayndh & & \multirow{2}{*}{$\begin{array}{l}\text { B } \\
\text { environmental }\end{array}$} \\
\hline 2 & Lack of natural hazards & & \\
\hline 2 & The appropriateness of form Site & \multirow{3}{*}{2} & \multirow{3}{*}{$\begin{array}{l}\text { D } \\
\text { Site }\end{array}$} \\
\hline 3 & Vision and perspective Site & & \\
\hline 1 & User agrees neighborhoods Site & & \\
\hline 1 & National land ownership & & $\mathrm{E}$ \\
\hline 2 & Wastelands & & Ownership \\
\hline
\end{tabular}

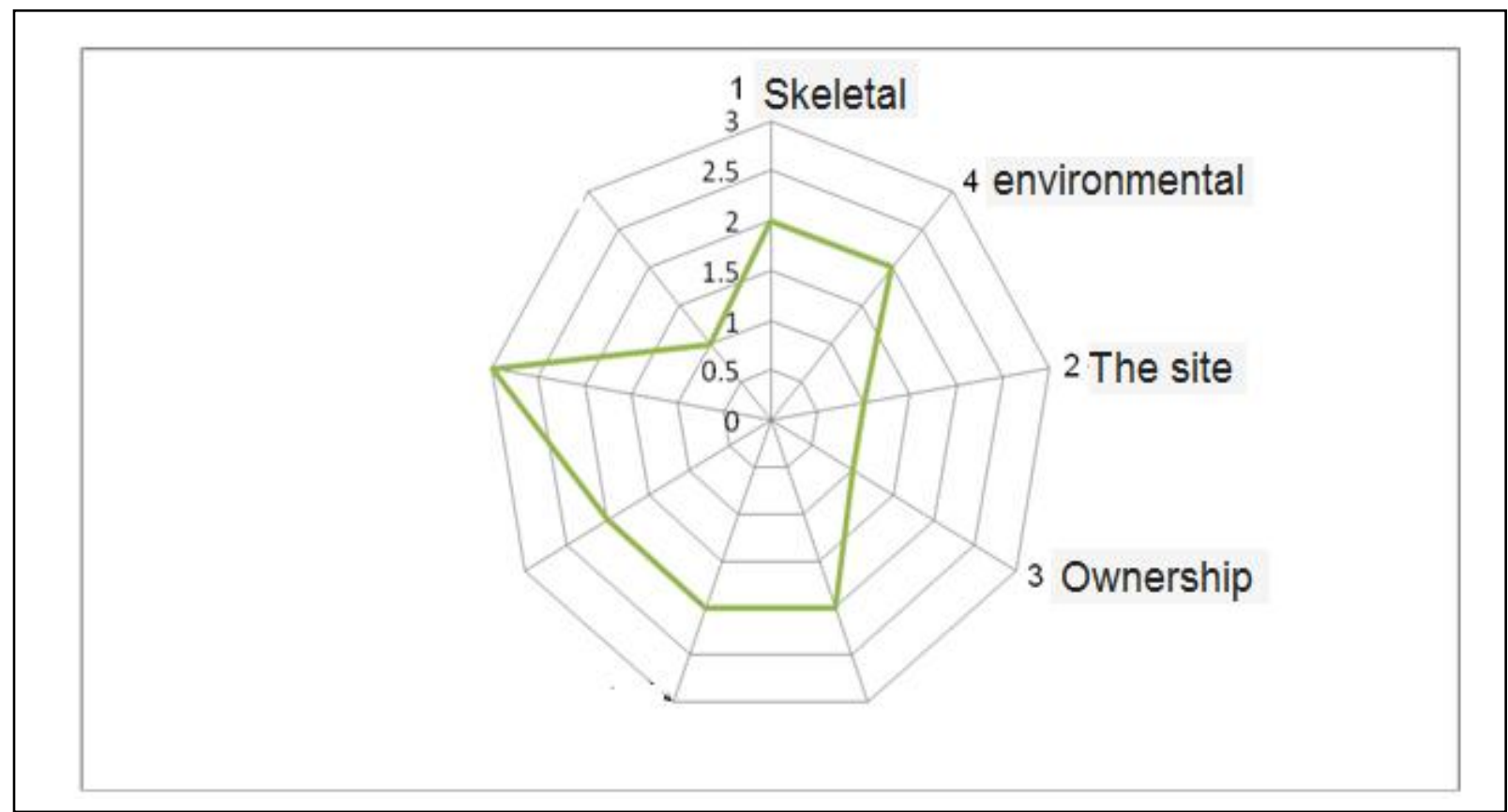

Figure1: the priorities of the criteria and sub-criteria

There are infrastructure services based on data Damghan Housing and Urban Development, the project has a full service infrastructure.

Land ownership: land ownership housing cover of the national territory is used.

\subsection{Value Site}

Site functionality neighborhood consistent: 65 percent good and 35 percent are middle of the match. Fit the size, form and shape of the site: $83 \%$ are in good condition, $10 \%$ moderate and 7 percent are poor Vision and perspective of the site: $85 \%$ good and $15 \%$ average.

\subsection{Other Survey Measures of Locating Housing Damghan}

Mehr housing project in Damghan, almost has the consistency. In addition, there is strong pressure and Makzhan fuel pylon next to the project of the non-compliance of applications can be named. Finally, to determine the location of housing projects according to priority criteria and sub-criteria cover positioning, mapping matrix methods have been used. This matrix can be seen as the last line, the location was almost as good.

\section{Conclusion}

In this study, in order to set goals and wisdom, is trying to introduce the Analytic Hierarchy Process (AHP) and the method of weighting the data layers involved in locating and describing the process of introducing criteria, sub-criteria for optimal positioning residential land was discussed. Criteria examined mainly physical measures, socio-cultural, environmental, economic, legal and land ownership, the site is. In this article due to the extent of over-the issue of expansion of economic criteria, social avoided. But other criteria relevant sub-criteria in the form of analytical tables are listed separately. The results of the evaluation questionnaire distributed among experts in urban planning and housing, and weighting the criteria through AHP method shows that access criteria and location are the most important role in the location of residential land have. And then to the environmental criteria, physical, land ownership and value of the site. The sub-criteria related to each criterion are also ranked. In the form of field studies locating housing projects according to the criteria and subcriteria ranking Damghan were analyzed. For this data. Required in the form of a questionnaire was developed by the experts Mksn Damghan is completed. Then the data in tables and charts and matrix analysis of qualitative evaluation criteria and sub-criteria were drawn final priority coefficients intervention. possible location is ideal.

\section{Reference}

[1] Mighty, A., (1392), "housing development in Damghan, with an emphasis on housing," Master thesis Architecture Islamic Azad University.

Pourahmad, Ahmad Habibi, K., M. Zahraei, Sajjad, justice, Saeed Nazari (1386), using fuzzy algorithms and GIS to locate municipal equipment, input study: landfill Babolsar, ecology and thirtieth year Issue 42, summer, pp. 42 and 43.

[2] success, Feroz (1369), set the topics and methods of Housing Urban Development, Urban Planning and Architecture Studies and Research Center, Department of Housing and Urban Development, 
First Editions prophetic, Syed Ehsan (1384), provided innovative use of sustainable building materials (in-house with minimal cost Habibi, Seyyed Mohsen, Ahari, Z. (1367), "minimal housing". Building and Housing Research Center, Tehran. Hosseini, Ali (1379), evaluation of educational applications Tehran, to see the pattern area 15, the end of a Master of Urban Planning, University of Madras. Dusty, G. (1378), with a view to the dissertation research method ", Scientific Research Center, Tehran.

[3] skilled, Esfandiar (1380), the use of hierarchical analysis and logic of urban planning, fine arts magazine, No. 10, Tehran, pp. 13 to 21 . Talib, M. (1370), "How Social Studies", published by Amir Kabir, Tehran.

Azizi, M., 1383, "the index of housing housing in the planning process", Journal of Fine Arts, (17).

[4] odd FAZELNIA, Akbar Kiani, Moses blessed (1379), the optimal location for sport spaces the city by using Analytical Hierarchy Process (AHP) and Geographic Information Systems GIS, University of Zanjan, Iran, Journal of Urban Planning, the first year, the first issue, summer, pp. 1 to 20.Gharagozlou, A. (1384), the development of urban functions with the use of ecological models and the use of GIS and RS, Shhrngar, No. 50, 36, 32 .

[5] Center for Urban Development and Architecture Department of Urban Studies and Research. 1389-1390.center studies and specialized services in urban and rural Institute for Humanities and Social Sciences (SID), the country's municipalities and Dehdari (1389), a series of specialized texts mayors, geographic information systems(GIS), p. 24.Department of Housing and Urban Development,Housing and Urban Development Semnan. some criteria rural location, Islamic Revolution Housing Foundation Rural Affairs.

[6] Abdoli, M,A.(1990).Landfill and retrieve of urban solid waste management in Iran. Study

[7] center of urban planning - Ministry of interior affiairs, Tehran: Municiplitary Organization. Chen, Y. :Yu, J. and Khan, S. (2010), Spatial sensitivity analysis of multi- criteria weights in GIS- based land suitability evaluation, Environmental Medelling \& Software, Volume 25, Issue 12, December 2010. Pages 1582- 1591.

[8] Vahidnia, Mohammad H. and Slesheikh, Ali A. and Alimohammadi, Abbas, (2009). Hospital site selection using fuzzy AHP and its derivatives, Journal of Environmental Management, Volume 90, Issue July 2009 , 